\title{
PROJETO ATLAS LINGUÍSTICO DO BRASIL (ALiB): A REALIZAÇÃO DE /T, D/ DIANTE DE [I] EM CARUARU E GARANHUNS - PE
}

\section{Caroline Lima Bulcão ${ }^{\mathbf{1}}$; Josane Moreira de Oliveira ${ }^{2}$}

1. Bolsista PIBIC/CNPq, Graduando em Letras Vernáculas, Universidade Estadual de Feira de Santana, e-mail: carollimabulcao@gmail.com

2. Orientador, Departamento de Letras e Artes, Universidade Estadual de Feira de Santana, e-mail: josanemoreira@hotmail.com

PALAVRAS-CHAVE: Palatalização de /t, d/; Variação linguística; Português de Pernambuco.

\section{INTRODUÇÃO}

Desde o início do século XIX, a dialetologia se firma como ramo dos estudos linguísticos ocupando-se das áreas rurais, mas atualmente envolve também as áreas urbanas. O Projeto ALiB (Atlas Linguístico do Brasil) nasceu em 1996 e os primeiros volumes do Atlas foram publicados em 2014. Trata-se de um atlas pluridimensional, que considera, ao lado da dimensão diatópica, variáveis sociais tais como sexo, faixa etária e escolaridade.

Três razões são apontadas para o seu empreendimento: a) a inexistência de uma caracterização geral do português do Brasil a partir de dados coletados in loco; b) a ausência de dados que permitissem traçar uma divisão dialetal do nosso país; c) a necessidade de conhecimento da multidimensionalidade da língua do país para precisar e demarcar espaços geolinguísticos e para um melhor equacionamento da realidade de cada área e do ensino de Língua Portuguesa (CARDOSO, 1996).

Vinculada ao Projeto ALiB, desenvolve-se a pesquisa sobre a realização de /t, d/ diante de /i/ no Nordeste e no Brasil (OLIVEIRA et al., 2014; MOTA e OLIVEIRA, 2015), que pode ser alveolar ou palatal em palavras como tia, dia, leite, desde.

Nesta pesquisa, vinculada à anterior, investigou-se a realização de $/ \mathrm{t}, \mathrm{d} / \mathrm{diante}$ de [i] em duas cidades de Pernambuco (Caruaru e Garanhuns), que integram a rede de pontos do ALiB, contribuindo, portanto, para o avanço do mapeamento e da descrição do português brasileiro.

Além de contribuir com o Projeto ALiB nacional, investigando um fenômeno variável em cidades nordestinas, os resultados poderão fornecer base, a partir de dados empíricos, para combater o preconceito linguístico em relação a algumas pronúncias, sobretudo nordestinas, e para repensar o ensino-aprendizagem de língua portuguesa. 


\section{MATERIAL E MÉTODOS OU METODOLOGIA (ou equivalente)}

Esta pesquisa segue o quadro teórico-metodológico da Dialetologia e da Sociolinguística Laboviana (LABOV, 2008[1972], 1994, 2001, 2010).

Assim, para a análise da realização variável de /t, d/ diante de [i], foram considerados dados de duas localidades pernambucanas (Caruaru - ponto 69 e Garanhuns - ponto 72) que integram a rede de pontos do Projeto ALiB, o que perfaz um total de 8 (oito) informantes, e foram controladas variáveis linguísticas e sociais, além da variável geográfica, que condicionam a realização dento-alveolar ou palatalizada das consoantes /t/ e /d/ diante da vogal [i].

De acordo com a metodologia do Projeto ALiB, em cada cidade do interior foram inquiridos quatro informantes, dois homens e duas mulheres, todos com nível fundamental incompleto de escolaridade, sendo dois informantes da faixa etária mais jovem (18 a 30 anos) e dois da faixa etária mais avançada (50 a 65 anos). Assim, nesta pesquisa, foram analisados dados de um total de oito informantes e foram controladas variáveis linguísticas e sociais, além da variável geográfica, que podem condicionar a realização dento-alveolar ou palatalizada das consoantes /t, d/ diante da vogal [i].

Nesta pesquisa, foram controlados a localidade, o sexo e a faixa etária do informante bem como variáveis linguísticas elencadas no Quadro 1, a seguir:

Quadro 1: Variáveis controladas na pesquisa

\begin{tabular}{|l|l|}
\hline \multicolumn{1}{|c|}{ Variáveis linguísticas } & \multicolumn{1}{|c|}{ Variáveis extralinguísticas } \\
\hline $\begin{array}{l}\text { Natureza da consoante: consoante surda /t/ } \\
\text { ou sonora /d/ }\end{array}$ & Cidade: Caruaru ou Garanhuns \\
\hline Natureza da vogal: fonológica ou derivada ${ }^{1}$ & Sexo: masculino ou feminino \\
\hline Posição da sílaba: inicial, medial ou final & $\begin{array}{l}\text { Faixa etária: 18 a 30 anos (faixa 1) ou } 50 \text { a } \\
65 \text { anos (faixa 2) }\end{array}$ \\
\hline Tonicidade da sílaba: tônica ou átona & $\begin{array}{l}\text { Tipo de registro: mais monitorado (QFF e } \\
\text { QSL), ou menos monitorado (outras partes } \\
\text { do inquérito, exceto leitura) }\end{array}$ \\
\hline
\end{tabular}

\footnotetext{
${ }^{1}$ Considera-se vogal fonológica quando a única realização possível é [i], como em tía, $\underline{\text { dia }}$. Considera-se vogal derivada quando a realização [i] é possível, mas não exclusiva, como em parte, tarde, quando é possível a realização [e], pelo menos em alguns dialetos do Sul do Brasil.
} 


\begin{tabular}{|l|l|}
\hline $\begin{array}{l}\text { Vogal antecedente: [a, ã], [E, e, ẽ], [i, ̃̃], [o, } \\
\text { õ], [u, ũ], semivogal anterior [y] ou } \\
\text { semivogal posterior [w] }\end{array}$ & \\
\hline $\begin{array}{l}\text { Consoante antecedente: constritiva } \\
\text { alveolar, constritiva palatal ou constritiva } \\
\text { laríngea, velar ou vibrante }\end{array}$ & \\
\hline $\begin{array}{l}\text { Nasalidade da vogal: oral ou nasal } \\
\text { Classe de palavra: substantivo, adjetivo, } \\
\text { verbo, pronome, numeral, advérbio, } \\
\text { preposição }\end{array}$ & \\
\hline
\end{tabular}

Os dados foram extraídos das respostas ao Questionário Fonético-Fonológico (QFF), ao Questionário Semântico-Lexical (QSL) e ao Questionário Morfossintático do ALiB (cf. COMITÊ NACIONAL, 2001) e de ocorrências em outras partes do inquérito (temas de discurso livre), com exceção do texto para leitura.

Após ouvidos e transcritos foneticamente, os dados foram codificados e submetidos ao Programa GoldVarb X (SANKOFF; TAGLIAMONTE; SMITH, 2005) para processamento computadorizado. Após cálculos de análise combinatória, o programa gerou as frequências, os pesos relativos e o nível de significância de cada fator e de cada grupo de fatores.

\section{RESULTADOS E/OU DISCUSSÃO (ou Análise e discussão dos resultados)}

A pesquisa revelou que as comunidades pernambucanas estudadas caracterizamse, em grande maioria, pela realização dento-alveolar de /t, d/ diante [i], pois, de um total de 3050 dados, apenas 533 (17,5\%) foram de realizações palatal.

Tabela 1: Resultado geral para /t, d/ diante de [i] (vogal derivada e fonológica)

\begin{tabular}{l|c|c}
\multicolumn{1}{c|}{ Variantes } & Ocorrências & Porcentuais \\
\hline Palatal & 533 & $17,5 \%$ \\
\hline Dento alveolar & 2517 & $82,5 \%$ \\
\hline Total & 3050 & $100 \%$ \\
\hline
\end{tabular}

Exemplificam a realização palatal [t $\mathrm{t} \mathrm{i}]$ pos, assis[t $\left.\int \mathrm{i}\right] r$, [d3i]strito, jar[d3i]neiro.

Exemplificam a realização dento-alveolar pra[ti]camen[ti], ado[ti]vo, [di]sse, mé[di]cos. 


\subsection{VARIÁVEIS SELECIONADAS}

Submetidos os dados ao Programa GoldVarb X tendo com regra de aplicação a realização palatal, o input inicial foi 0,175 , o input final foi 0,269, o log likelihood foi 1284,293 e o nível de significância foi 0,009. As variáveis selecionadas como estatisticamente relevantes foram, nesta ordem: 'Consoante precedente', 'Tonicidade da sílaba', 'Cidade', 'Vogal precedente', 'Faixa etária', 'Sexo', 'Natureza da vogal', 'Classe de palavra' e 'Natureza da consoante'. Serão apresentadas primeiramente as variáveis linguísticas e depois as extralinguísticas. A seguir, serão comentadas brevemente as variáveis descartadas: 'Posição na sílaba', 'Nasalidade da vogal' e 'Tipo de registro'.

\subsubsection{Consoante precedente}

Algumas ocorrências de /t, d/ diante de [i] aparecem em palavras com sílaba anterior travada por consoante [S] palatal, [s] sibilante ou [h] faríngea (ou velar ou glotal). Essas consoantes precedentes podem ocorrer em palavras como destino, prostituta, tarde e sorte. Os resultados encontrados nesse contexto estão apresentados na Tabela 1, abaixo.

Tabela 1: Palatalização e 'Consoante precedente'

\begin{tabular}{c|c|c|c}
\hline $\begin{array}{c}\text { Consoante } \\
\text { precedente }\end{array}$ & Ocorrências/Total & Percentual & Peso Relativo \\
\hline Palatal: $\left[\int, 3\right]$ & $48 / 55$ & $87,3 \%$ & $\mathbf{0 , 9 4 0}$ \\
\hline Sibilante: $[\mathrm{s}, \mathrm{z}]$ & $6 / 18$ & $33,3 \%$ & 0,471 \\
\hline Faríngea: $[\mathrm{h}]$ & $17 / 145$ & $11,7 \%$ & 0,263 \\
\hline
\end{tabular}

Favorece a palatalização de /t, d/ diante de [i] a consoante precedente palatal,

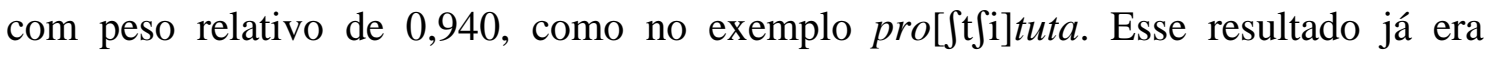
esperado, pois o processo de assimilação é bastante comum nas línguas naturais, o que justifica também ter sido a variável 'Consoante precedente' a primeira selecionada pelo programa de regras variáveis. A realização sibilante do arquifonema /S/ em sílaba anterior, como em norde[sti], inibe a palatalização (peso relativo de 0,471), assim como a consoante $/ \mathrm{R} /$, que pode ser faríngea, velar ou glotal, como em transpo[hti] (peso relativo de 0,263 ). 


\subsubsection{Tonicidade da sílaba}

Controlando a variável 'Tonicidade da sílaba', os dados foram agrupados em /t, d/ diante de [i] em sílaba tônica, como em batatinha e moradia, e /t, d/ diante de [i] em sílaba átona, como em particular e diferença. A Tabela 2, abaixo, mostra os resultados para essa variável, a segunda selecionada pelo GoldVarb X:

Tabela 2: Palatalização e 'Tonicidade da sílaba'

\begin{tabular}{c|c|c|c}
\hline $\begin{array}{c}\text { Tonicidade da } \\
\text { sílaba }\end{array}$ & Ocorrências/Total & Percentual & Peso Relativo \\
\hline Átona & $356 / 1722$ & $20,7 \%$ & $\mathbf{0 , 6 0 5}$ \\
\hline Tônica & $177 / 1328$ & $13,3 \%$ & 0,365 \\
\hline
\end{tabular}

Favorecem a palatalização de /t, d/ diante de [i] as sílabas átonas, com peso relativo de 0,605. Já as sílabas tônicas inibem a realização palatal, com peso relativo de 0,365, conforme a hipótese levantada nesta pesquisa, já que as sílabas tônicas requerem maior tensão articulatória, favorecendo a realização de fones considerados padrão em determinada comunidade de fala.

\subsubsection{Vogal precedente}

O controle da variável 'Vogal precedente' foi feito para que se pudesse observar a atuação da zona de articulação da vogal que precede /t, d/ diante de [i], pois se levantou a hipótese de que quanto mais posterior a vogal precedente maior a aplicação da regra de palatalização por um processo assimilatório. Também era esperado que a vogal [i], também chamada de vogal palatal, favorecesse a palatalização de /t, d/.

São exemplos de dados com vogal precedente [a]: prateleira e cidade. A vogal /E/ precedente foi documentada em dados como apetite e cedinho. Com a vogal /i/ foram encontrados dados como grafite e liquidificador. Dados com a vogal /O/ precedente podem ser exemplificados em adotivo e bode. Já com a vogal /u/ precedente foram documentados dados como sutiã e açude. Os resultados encontrados para essa variável estão expostos na Tabela 3:

Tabela 3: Palatalização e 'Vogal precedente'

\begin{tabular}{c|c|c|c}
\hline Vogal precedente & Ocorrências/Total & Percentual & Peso Relativo \\
\hline$/ \mathrm{i} /$ & $37 / 140$ & $26,4 \%$ & $\mathbf{0 , 6 1 5}$ \\
\hline$/ \mathrm{E} /$ & $95 / 524$ & $18,1 \%$ & $\mathbf{0 , 5 0 5}$ \\
\hline$/ \mathrm{a} /$ & $69 / 366$ & $18,9 \%$ & $\mathbf{0 , 5 1 8}$ \\
\hline$/ \mathrm{O} /$ & $37 / 197$ & $18,8 \%$ & $\mathbf{0 , 5 5 7}$ \\
\hline$/ \mathrm{u} /$ & $4 / 90$ & $4,4 \%$ & 0,163 \\
\hline
\end{tabular}


Como era esperado, a vogal /i/ foi a que mais favoreceu a palatalização, por ter também esse traço em sua articulação, com peso relativo de 0,615 . As vogais /E/, /a/ e /O/ também favorecem a palatalização, mas com pesos menores que o da vogal /i/. Já a vogal alta posterior / $\mathrm{u} /$ inibe a palatalização de /t, d/ diante de [i], com peso relativo de 0,163 , tendo a palatalização ocorrido em apenas quatro dados com esse contexto.

\subsubsection{Natureza da vogal}

A variável 'Natureza da vogal' diz respeito ao fato de a vogal [i] ser fonológica, como em tía, tíara, dị a díabo, ou ser derivada, como em prateleira, deficiente, destruído e oportunidade . E a hipótese aventada foi a de que a palatalização fosse favorecida em contexto de vogal fonológica, cuja realização é categórica, com articulação palatal, pois no caso da vogal derivada, sua articulação é variável, podendo ser [i] ou [e]. A Tabela 4, a seguir, apresenta os resultados para a natureza da vogal.

Tabela 4: Palatalização e 'Natureza da vogal'

\begin{tabular}{c|c|c|c}
\hline Natureza da vogal & Ocorrências/Total & Percentual & Peso Relativo \\
\hline Fonológica & $217 / 1101$ & $19,7 \%$ & $\mathbf{0 , 5 8 1}$ \\
\hline Derivada & $316 / 1949$ & $16,2 \%$ & 0,454 \\
\hline
\end{tabular}

Em termos percentuais, a palatalização de /t, d/ diante de [i] foi atestada em menos de $20 \%$ dos dados, tendo sido um pouco mais frequente com o /i/ fonológico do que com o [i] derivado. Mas, considerando os pesos relativos encontrados, percebe-se que a vogal fonológica favorece a palatalização, com peso relativo de 0,581 , e a vogal derivada a inibe, com peso relativo de 0,454 , confirmando a hipótese aventada.

\subsubsection{Classe de palavra}

As palavras foram agrupadas por classe gramaticais, variável também controlada nesta pesquisa. Seguem exemplos de palavras com /t, d/ diante de [i] pertencentes às classes consideradas: preposição - $\underline{\text { de}}$; verbo - encoste ; pronome - $\underline{t}$; numeral - sete ; substantivo - açude; adjetivo - $\underline{\text { diferente }}$; e advérbio - antigamente. A Tabela 5, abaixo, exibe os resultados encontrados.

Tabela 5: Palatalização e 'Classe de palavra'

\begin{tabular}{c|c|c|c}
\hline Classe de palavra & Ocorrências/Total & Percentual & Peso Relativo \\
\hline Preposição & $99 / 793$ & $12,5 \%$ & $\mathbf{0 , 6 4 5}$ \\
\hline Verbo & $113 / 497$ & $22,7 \%$ & $\mathbf{0 , 5 3 7}$ \\
\hline Pronome & $2 / 19$ & $10,5 \%$ & 0,497 \\
\hline Numeral & $6 / 27$ & $22,2 \%$ & 0,433 \\
\hline Substantivo & $221 / 1199$ & $18,4 \%$ & 0,426 \\
\hline
\end{tabular}




\begin{tabular}{c|c|c|c}
\hline Adjetivo & $62 / 344$ & $18 \%$ & 0,418 \\
\hline Advérbio & $30 / 169$ & $17,8 \%$ & 0,402 \\
\hline
\end{tabular}

Como se pode ver na Tabela 5, acima, apenas as classes das preposições e dos verbos favorecem a palatalização de /t, d/ diante de [i], com presos relativos de 0,645 e 0,537, respectivamente. Cumpre ressaltar a alta produtividade da preposição de no corpus analisado, grande responsável pela maioria dos dados da classe das preposições, que só perde, em frequência, para os substantivos. As demais classes gramaticais (pronome, numeral, substantivo, adjetivo e advérbio) inibem a palatalização dos segmentos estudados.

\subsubsection{Natureza da consoante}

Nesta pesquisa, controlou-se também a natureza (ou vozeamento) da consoante surda /t/ ou sonora /d/ - afetada pelo processo de palatalização. São exemplos de dados com a consoante surda tío e gente. São exemplos de dados com a consoante sonora día e idade. A hipótese aventada no controle dessa variável foi a de que o /t/ fosse mais favorável à palatalização do que o /d/, como atestaram Mota e Oliveira (2015) analisando dados das capitais brasileiras integrantes da rede de pontos do Projeto ALiB. Na Tabela 6, a seguir, estão apresentados os resultados encontrados para essa variável.

Tabela 6: Palatalização e 'Natureza da consoante'

\begin{tabular}{c|c|c|c}
\hline $\begin{array}{c}\text { Natureza da } \\
\text { consoante }\end{array}$ & Ocorrências/Total & Percentual & Peso Relativo \\
\hline Surda: $/ \mathrm{t} /$ & $261 / 1148$ & $22,7 \%$ & $\mathbf{0 , 5 5 5}$ \\
\hline Sonora: $/ \mathrm{d} /$ & $272 / 1902$ & $14,3 \%$ & 0,467 \\
\hline
\end{tabular}

Das 1148 ocorrências da consoante surda /t/ diante de [i], 261 foram com a realização palatal, correspondendo a $22,7 \%$ dos dados, com peso relativo de 0,555 , favorecendo a palatalização. Dos 1902 casos da consoante sonora /d/ diante de [i], 272 foram com a realização palatal, correspondendo a 14,3\% dos dados, com peso relativo de 0,467 , inibindo a palatalização. Os resultados desta pesquisa confirmam a hipótese aventada e corroboram os resultados de Mota e Oliveira (2015).

\subsubsection{Cidade}

A variável 'Cidade' foi a terceira selecionada pelo GoldVarb X, a primeira variável extralinguística na ordem de seleção do programa. Num estudo de caráter geosociolinguístico com base em dados do Atlas Linguístico do Brasil, a seleção dessa 
variável é mito importante, pois pode servir de base para uma proposta de divisão dialetal do Brasil.

A Tabela 7, abaixo, exibe os resultados para a palatalização de /t, d/ diante de [i] nas duas cidades pesquisadas.

Tabela 7: Palatalização e 'Cidade'

\begin{tabular}{c|c|c|c}
\hline Cidade & Ocorrências/Total & Percentual & Peso Relativo \\
\hline Garanhuns & $346 / 1681$ & $20,6 \%$ & $\mathbf{0 , 5 6 5}$ \\
\hline Caruaru & $187 / 1369$ & $13,7 \%$ & 0,421 \\
\hline
\end{tabular}

Das 1681 ocorrências de /t, d/ diante de [i] documentadas na cidade de Garanhuns, 346 foram de realização palatal, o que corresponde a 20,6\% dos dados, com peso relativo de 0,565, favorecendo a palatalização. Das 1369 ocorrências de /t, d/ diante de [i] na cidade de Caruaru, 187 foram de realização palatal, o que corresponde a $13,7 \%$ dos dados, com peso relativo de 0,421 , inibindo a palatalização.

\subsubsection{Faixa etária}

A variável 'Faixa etária' é determinante num estudo em tempo aparente, pois pode revelar mudança em progresso ou variação estável de um determinado fenômeno. Nesta pesquisa, aventou-se a hipótese de que os mais velhos palatalizassem menos do que os mais jovens, considerando que a realização de /t, d/ diante de [i] é majoritária nas capitais brasileiras e é a variante de maior prestígio social no País (MOTA; OLIVEIRA, 2015).

Os resultados desta análise estão apresentados da Tabela 8, a seguir.

Tabela 8: Palatalização e 'Faixa etária'

\begin{tabular}{c|c|c|c}
\hline Faixa etária & Ocorrências/Total & Percentual & Peso Relativo \\
\hline 18 a 30 anos & $265 / 1714$ & $15,5 \%$ & 0,462 \\
\hline 50 a 65 anos & $268 / 1336$ & $20,1 \%$ & $\mathbf{0 , 5 4 9}$ \\
\hline
\end{tabular}

Na faixa etária de 18 a 30 anos (Faixa 1), dos 1714 dados de /t, d/ diante de [i], 265 foram de realização palatal (15,5\%), apresentando peso relativo de 0,465 , inibindo a palatalização. Já na faixa etária de 50 a 65 anos (Faixa 2), ocorreram 1336 casos de /t, d/ diante de [i], 268 dos quais foram de realização palatal (20,1\%), com peso relativo de 0,549, favorecendo a palatalização. A hipótese assumida foi, pois, descartada.

Nas cidades consideradas nesta pesquisa, os informantes mais novos não viajavam muito e não tinham acesso a meios de comunicação de massa, como televisão e Internet, por diversos fatores, entre eles o trabalho, que ocupava muito do seu tempo. 
Os mais velhos das duas cidades assistiam à televisão e ouviam rádio, alguns frequentavam igrejas e tinham filhos em outras cidades. Esses fatores facilitavam o contato desses informantes com a variante palatalizada, e esse contato interdialetal pode ter influenciado a fala dessas pessoas. Pode-se pensar também que os mais jovens mantêm a realização dento-alveolar de /t, d/ diante de [i] como forma de reafirmar a identidade do dialeto local, o que requer estudos posteriores que averiguem essa hipótese.

\subsubsection{Sexo}

A variável 'Sexo' também é importante nos estudos de variação e mudança linguística. Os papéis sociais de homens e mulheres são diferentes a depender da realidade sócio-histórico-cultural das comunidades. Em geral, quando se trata de uma mudança em direção a variantes de prestígio, as mulheres tomam a liderança. Assim, aventou-se a hipótese de que as mulheres palatalizariam mais do que os homens nas cidades pesquisadas. Os resultados encontrados estão na Tabela 9, abaixo.

Tabela 9: Palatalização e 'Sexo'

\begin{tabular}{c|c|c|c}
\hline Sexo & Ocorrências/Total & Percentual & Peso Relativo \\
\hline Feminino & $280 / 1477$ & $19 \%$ & $\mathbf{0 , 5 3 5}$ \\
\hline Masculino & $253 / 1573$ & $16,1 \%$ & 0,468 \\
\hline
\end{tabular}

As mulheres apresentaram 1477 ocorrências de /t, d/ diante de [i], dos quais 280 foram de realização palatal, o que corresponde a $19 \%$ dos dados, com peso relativo de 0,535, favorecendo a palatalização. Das 1573 ocorrências de /t, d/ diante de [i] obtidas dos homens, 253 foram de realização palatal, correspondendo a 16,1\% dos dados, com peso relativo de 0,468, inibindo a palatalização. Assim, confirmando a hipótese assumida, as mulheres são mais inovadoras.

No caso dessas mulheres que foram informantes do Projeto ALiB, pelo que se pode atestar nas entrevistas, assistem mais televisão do que os homens. Nas novelas que algumas delas assistem, a variante mais usada é a palatal, que tem maior prestígio no Brasil. Isso pode explicar o fato de terem se comportado linguisticamente como inovadoras, palatalizando mais do que os homens.

\subsection{VARIÁVEIS DESCARTADAS}

De todas as variáveis controladas na pesquisa, como exposto no Quadro 1, apenas três foram descartadas pelo GoldVarb X como estatisticamente irrelevantes: 
'Posição da sílaba' (inicial - tesoura e desmaio; medial - futebol e redemoinho; ou final - noite e cidade); 'Nasalidade da vogal' (oral - vinte e tarde; ou nasal - catingoso e dinheiro); e 'Tipo de registro' (mais monitorado - QFF e QSL; ou menos monitorado outras partes do inquérito, exceto texto para leitura).

A título de ilustração, os resultados percentuais para essas variáveis estão apresentados na Tabela 10, a seguir.

Tabela 10: Índices de palatalização nas variáveis descartadas

\begin{tabular}{l|l|c|c}
\hline \multicolumn{1}{c|}{ Variável } & \multicolumn{1}{|c|}{ Fatores } & Ocorrências/Total & Percentual \\
\hline Posição da sílaba & Inicial & $220 / 1517$ & $14,5 \%$ \\
& Medial & $103 / 471$ & $\mathbf{2 1 , 9 \%}$ \\
& Final & $210 / 1062$ & $19,8 \%$ \\
\hline Nasalidade da vogal & Oral & $528 / 3023$ & $17,5 \%$ \\
& Nasal & $5 / 27$ & $\mathbf{1 8 , 5 \%}$ \\
\hline Tipo de registro & Mais monitorado & $381 / 2092$ & $\mathbf{1 8 , 2 \%}$ \\
& Menos monitorado & $152 / 958$ & $15,9 \%$ \\
\hline
\end{tabular}

Considerando apenas os percentuais, observa-se que a palatalização de /t, d/ diante de [i] foi mais frequente em sílabas mediais, com a vogal [i] nasal e no estilo mais monitorado, quando, possivelmente, o informante foi influenciado pela articulação do entrevistador, que empregava a variante palatal. Só com a ampliação do corpus e com a continuidade da pesquisa essas variáveis podem ser melhor analisadas.

\section{CONSIDERAÇÕES FINAIS (ou Conclusão)}

Analisou-se, a partir do aporte teórico-metodológico da Sociolinguística e da Dialetologia, a realização variável de /t, d/ diante de [i] (realização dento-alveolar ou palatalizada) em dados das cidades de Caruaru e Garanhuns, no interior de Pernambuco, integrantes da rede de pontos do Projeto ALiB. Para tanto, foram controladas variáveis linguísticas e extralinguísticas e utilizou-se o Programa GoldVarb X para processamento estatístico dos dados, coletados após audição e transcrição fonética dos mesmos em oito entrevistas, quatro de cada cidade. Os informantes foram estratificados em sexo (masculino ou feminino) e faixa etária (18 a 30 anos - Faixa 1 ou 50 a 65 anos - Faixa 2), todos com nível fundamental de escolaridade.

Dos 3050 dados coletados que compuseram o corpus da pesquisa, $533(17,5 \%)$ foram de realização palatal de /t, d/ diante de [i], contra 2517 (82,5\%) de realização dento-alveolar, o que revela que nessas comunidades o padrão regular é a realização não-palatalizada. Considerando como regra de aplicação a realização palatalizada, considerada inovadora do ponto de vista histórico e variante de maior prestígio no 
português brasileiro, foram selecionadas como estatisticamente relevantes as variáveis 'Consoante precedente', 'Tonicidade da sílaba', 'Cidade', 'Vogal precedente', 'Faixa etária', 'Sexo', 'Natureza da vogal', 'Classe de palavra' e 'Natureza da consoante', tendo sido descartadas variáveis 'Posição na sílaba', 'Nasalidade da vogal' e 'Tipo de registro'.

Quanto à 'Consoante precedente', favorecem a realização palatal de /t, d/ diante

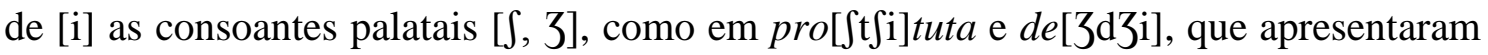
peso relativo de 0,940. A regra de palatalização também é favorecida nas sílabas átonas, que apresentaram peso relativo de 0,605, em palavras como noite e desvio. As vogais precedentes /i, E, a, O/ favorecem a palatalização dos segmentos analisados, com destaque para a vogal /i/, como em vinte e esqueci de novo, que apresentou o maior peso relativo $(0,615)$. As consoantes $/ t, d /$ têm palatalização favorecida quando articuladas diante de /i/ vogal fonológica, como em tíara e diabo, que alcançou o peso relativo de 0,581. As classes de palavras Preposição e Verbo favorecem a palatalização de /t, d/ diante de [i], com pesos relativos de 0,645 e 0,537, respectivamente. Os resultados para a variável 'Natureza da consoante' revelam que a regra de palatalização é mais aplicada para a consoante surda $/ t /$, que apresentou peso relativo de 0,555 , do que para a consoante sonora /d/, que apresentou peso relativo de 0,467 , inibindo a realização palatalizada.

No que tange às variáveis extralinguísticas, a cidade de Garanhuns, que apresentou peso relativo de 0,565 , palataliza mais do que a cidade de Caruaru, cujo peso relativo foi de 0,421 . Quanto à 'Faixa etária', nas cidades examinadas, os informantes da faixa etária 2 (50 a 65 anos) palatalizam mais (peso relativo de 0,549) do que os da faixa etária 1 (18 a 30 anos), que apresentaram peso relativo de $(0,462)$. Nessas comunidades, as mulheres se mostraram mais inovadoras, apresentando peso relativo de 0,535 para a regra de palatalização de /t, $\mathrm{d} /$ diante de [i], contra o peso relativo de 0,468 alcançado pelos homens.

Em relação às variáveis descartadas, pode-se dizer que a realização palatal de /t, d/ diante de [i] foi mais frequente em sílaba medial, com a vogal [i] nasal e no registro mais monitorado.

Com os resultados da pesquisa apresentados neste artigo, espera-se contribuir para a descrição do português brasileiro e para a execução dos objetivos do Projeto Atlas Linguístico do Brasil. Reconhece-se, todavia, que o tema aqui estudado precisa ser aprofundado e estendido a outras comunidades. 


\section{REFERÊNCIAS}

ALKMIM, Tânia Maria. Sociolinguística: parte I. In: MUSSALIM, F.; BENTES, A. C. (Orgs.) Introdução à linguística. v. 1, $2^{\mathrm{a}}$ ed. São Paulo: Cortez, 2001, p. 21-47.

CALVET, Louis-Jean. Sociolinguística: uma introdução crítica. São Paulo: Parábola, 2002.

CAMACHO, Roberto Gomes. Sociolinguística: parte II. In: MUSSALIM, F.; BENTES, A. C. (Orgs.). Introdução à linguística. v. 1, $2^{\mathrm{a}}$ ed. São Paulo: Cortez, 2001, p. 49-75.

CARDOSO, S. A. O Atlas Linguístico do Brasil: uma questão política. Atas do Seminário Nacional Caminhos e Perspectivas para a Geolinguística no Brasil. Salvador: UFBA, 1996, p. 87-96.

CARDOSO, S. A. M. et al. (Orgs.). Atlas linguístico do Brasil, v. 1 (Introdução). Londrina: EDUEL, 2014a.

CARDOSO, S. A. M. et al. (Orgs.). Atlas linguístico do Brasil, v. 2 (Cartas linguísticas 1). Londrina: EDUEL, 2014b.

COMITÊ NACIONAL do Projeto ALiB. Atlas linguístico do Brasil. Questionários 2001. Londrina: UEL, 2001.

CONGRESSO BRASILEIRO DE LÍNGUA FALADA NO TEATRO, 1, 1956, Salvador. Anais... Rio de Janeiro: Ministério de Educação e Cultura, 1958.

GOOGLE Imagens. Disponível em: https://www.google.com/imghp?hl=pt-pt. Acesso em: 17 jun. 2018.

LABOV, W. Padrões sociolinguísticos. Trad. Marcos Bagno, Marta Scherre e Caroline Cardoso. São Paulo: Parábola, 2008[1972].

LUCENA, Isabella Cristina Amorim; CASTEDO, Tatiana Maranhão. Interrelações entre a Sociolinguística e a Dialetologia. Disponível em: <www.leffa.pro.br/tela4/Textos/Textos/Anais/ABRALIN_2009/PDF/Isabella\%20Cristi na\%20Amorin\%20de\%20Lucena\%20-\%20ok.pdf>. Acesso em: 21 jul. 2018.

MOLLICA, M. C. Fundamentação teórica: conceituação e delimitação. In: MOLLICA, M. C.; BRAGA, M. L. Introdução à sociolinguística: o tratamento da variação. São Paulo: Contexto, 2004, p. 9-14.

MONTEIRO, José Lemos. Morfologia portuguesa. $4^{\text {a }}$ ed. Campinas: Pontes, 2002.

MOTA, J. A.; OLIVEIRA, J. M. Cartas fonéticas. In: CARDOSO, S. A. M. et alii (Orgs.). Atlas Linguístico do Brasil, v. 2. Londrina: EDUEL, 2014, p. 123- 129.

MOTA, J. A.; OLIVEIRA, J. M. As consoantes oclusivas /t, d/ diante de [i] nas capitais brasileiras com base em dados do Atlas Linguístico do Brasil (ALiB). Trabalho entregue para publicação no volume 3 do Atlas Linguístico do Brasil (ALiB), 2015 (inédito).

OLIVEIRA, J. M.; MOTA, J. A.; CARDOSO, S. A. M. Variabilidade no português: a realização de /t, d/ diante de /i/ em dados do Atlas Linguístico do Brasil (ALiB). Comunicação apresentada no IV Congresso Internacional da AILP (Associação Internacional de Linguística do Português). Macau: Universidade de Macau, dez. 2014 (inédito).

SANKOFF, D.; TAGLIAMONTE, S.; SMITH, E. GoldVarb X - a multivariate analysis application. Toronto: Department of Linguistics; Ottawa: Department of Mathematics, 2005. 
SANTOS, Silvanete Silva. A realização de /t, d/ diante de [i] no interior do Maranhão: análise de dados do Projeto Atlas Linguístico do Brasil (ALiB). Feira de Santana: UEFS, 2018 (Trabalho de Conclusão de Curso).

SILVA NETO, S. Introdução ao estudo da língua portuguesa no Brasil. $5^{\mathrm{a}}$ ed. Rio de Janeiro: Presença, 1986 [1950].

TARALLO, F. A pesquisa sociolinguística. São Paulo: Ática, 2001.

WIKIPÉDIA. A enciclopédia livre. Disponível em: https://pt.wikipedia.org/wiki/Wikip\%C3\%A9dia:P\%C3\%A1gina_principal. Acesso em: 18 jun. 2018. 